\title{
Socios Protectores
}

\section{INSTITUCIONES}

University of California at Los Angeles Library

Los Angeles 24, Calif., E. U. A.

University of Chicago Libraries Periodicals Division

Chicago 37, Illinois, E. U. A.

Claremont College Library

The Honnold Library

Claremont, California, E. U. A.

University of Michigan

General Library

Ann Arbor, Michigan, E. U. A.

New York Public Library

5th Avenue \& 42nd St.

New York, New York, E. U. A.

University of North Carolina Library

Chapel Hill, North Carolina, E. U. A.
Pan American Union

Columbus Memorial Library

Washington, D. C., E. U. A.

Princeton University Library

Princeton, New Jersey, E. U. A.

Biblioteca-Universidad de Santo Domingo

Ciudad Trujillo

República Dominicana

University of Texas Library

Austin 12, Texas, E. U. A.

University of Washington Library

Seattle 5, Washington, E. U. A.

Wellesley College Library

Wellesley, Mass., E. U. A.

Williams College Library

Williamstown, Massachusetts,

E. U. A. 


\section{PERSONAS}

Dra. Estefanía Antuña Tavio

Calle $25 \mathrm{~N}^{\circ} 1115$, bajos. Vedado. Habana, Cuba.
Dra. Elena Calduch

Calle 27, No 1014. Apto. 7.

Vedado. Habana, Cuba.

Dra. María D. Rodríguez-Vicens

Calle 27 No 601, altos, Vedado

Habana, Cuba. 